LUNG CANCER

\title{
Type of wine and risk of lung cancer: a case-control study in Spain
}

\author{
A Ruano-Ravina, A Figueiras, J M Barros-Dios
}

Thorax 2004;59:981-985. doi: 10.1136/thx.2003.018861

See end of article for authors' affiliations

..........

Correspondence to: Dr J M Barros Dios, Department of Preventive Medicine and Public Health, School of Medicine, C/San Francisco $\mathrm{s} / \mathrm{n}$, University of Santiago de

Compostela, 15782

Santiago de Compostela

Spain; mrbarros@usc.es

Received

12 November 2003

Accepted 16 July 2004
Background: Few epidemiological studies have examined the effect of wine on the risk of lung cancer. A study was therefore undertaken to estimate the effect of wine consumption, both overall and by type of wine, on the risk of developing lung cancer.

Methods: A hospital based case-control study was conducted on 319 subjects ( 132 cases, 187 controls) in 1999-2000. All subjects were interviewed about their lifestyles with particular reference to alcohol consumption and tobacco use. The results were analysed using non-parametric logistic regression. The main outcome measure was the risk of lung cancer associated with consumption of wine and its individual types.

Results: A very slight but significant association was observed between the risk of lung cancer and white wine consumption (odds ratio (OR) 1.20 for each daily glass). Red wine consumption, on the other hand, had an OR of 0.43 (95\% $\mathrm{Cl} 0.19$ to 0.96 ), with each daily glass of red wine having an inverse association with the development of lung cancer (OR 0.87 (95\% Cl 0.77 to 0.99 )). There was no apparent association between lung cancer and consumption of beer or spirits.

Conclusions: These results suggest that the consumption of red wine is negatively associated with the development of lung cancer. Further studies are needed to test this finding in cancer induced laboratory animals.
L ung cancer is a troublesome health problem in Spain and is the leading cause of cancer deaths in men and the fifth -highest cause in women. ${ }^{1}$ Tobacco use is the principal risk factor, with $85-90 \%$ of all lung cancers being tobacco related. ${ }^{23}$ Diet has been shown to influence the development of this disease ${ }^{4}$ and alcohol may have a certain degree of influence, although its effect is not clear. ${ }^{56}$ Existing studies are contradictory, with some speculating on the possibility of a risk, mainly for heavy drinkers, ${ }^{78}$ and others indicating that alcohol intake has no effect on the development of lung cancer. ${ }^{910}$

Few epidemiological studies have investigated the effect of wine consumption, both in general and of a specific type, on the development of lung cancer. ${ }^{81-13}$ Moreover, most of these studies do not differentiate between red and white wine, a distinction that could well prove very important because of their different composition in terms of potentially antioxidant and anticarcinogenic substances such as tannins and resveratrol. This study therefore sought to ascertain the effect of wine-both overall and by type (red and white)—on the development of lung cancer.

\section{METHODS \\ Design, subjects, and settings}

A hospital based case-control study was conducted in the Santiago de Compostela Public Health District in north-west Spain in 1999-2000. ${ }^{14}$ This district covers an area of approximately 5000 square kilometres, has a population of nearly 500000 inhabitants, and includes rural, urban, and coastal zones. It has only one large hospital where all cases of lung cancer are diagnosed.

One hundred and thirty two cases with an anatomically and pathologically confirmed diagnosis of primary bronchopulmonary cancer (ICD 162, 9th revision) were enrolled in the study. The control group consisted of 187 sex-frequency matched subjects attending the Santiago University Teaching Hospital Preoperative Unit for non-tobacco related minor surgery. Only one case refused to participate in the study and all controls agreed to take part. Five controls were excluded because they had had previous cancer. Prevalent cases, those aged less than 30 years, those with a clinical history of any type of cancer, and those scheduled to undergo major surgery were all excluded. Approximately $90 \%$ of the controls were scheduled to have orthopaedic surgery, cataract surgery, or surgery for inguinal hernias. All subjects were interviewed at the same hospital using a questionnaire which asked about smoking habit, occupation, type and amount of wine consumed, and intake of beer and spirits. With respect to smoking, subjects were asked the number of daily cigarettes, duration of the smoking habit, years since quitting (in the case of ex-smokers), and type of tobacco consumed. Each subject was also classified according to whether or not he or she had worked in occupations at risk for lung cancer following the classification proposed by Ahrens and Merletti ${ }^{15}$ which has been used elsewhere. ${ }^{16}$ Subjects were considered to have been occupationally exposed if they had worked for more than 1 year in one of the occupations at risk for lung cancer.

Wine was classified by type as red, white, or rosé (a variety with a relatively high consumption in Spain). Subjects were asked the type of wine consumed (classified as "red", "white", "rosé", and "all types") and the daily intake in terms of number of glasses of each type. Analysis of the dose related effect on lung cancer required the exclusion of subjects who consumed different types of wine indiscriminately since there was no way of ascertaining the number of glasses drunk by type. We also asked for the daily consumption of beer and the weekly consumption of the following spirits: whisky, rum, gin, brandy, and aguardiente (a clear schnapps-like drink distilled from fermented fruit juice). The intake of the individual spirits was combined into total weekly consumption which allowed the creation of a continuous variable. A variable with the amount of total alcohol intake was duly calculated taking into account the 


\begin{tabular}{|c|c|c|}
\hline & Cases & Controls \\
\hline Sex (\% men) & 118 (89.4) & $164(87.7)$ \\
\hline Mean (SD) age (years) & $64.2(10.8)$ & $62.5(9.9)$ \\
\hline \multicolumn{3}{|l|}{ Tobacco consumption } \\
\hline Current smokers (\%) & $79(59.8)$ & $50(26.8)$ \\
\hline Mean (SD)* & $23.7(12.6)$ & $14.6(11.1)$ \\
\hline Median*ब & $21.7(14.9,31.0)$ & $13.0(5.4,20.6)$ \\
\hline Ex-smokers (\%) & $43(32.6)$ & $60(32.0)$ \\
\hline \multicolumn{3}{|c|}{ Carcinogenic exposure at work* } \\
\hline Yes $(\%)$ & $49(37.1)$ & $49(26.2)$ \\
\hline \multicolumn{3}{|c|}{ Type of wine consumption } \\
\hline Non-drinkers (\%) & $33(25.0)$ & $41(21.9)$ \\
\hline White (\%) & $26(19.7)$ & $9(4.8)$ \\
\hline $\operatorname{Red}(\%)$ & $47(35.8)$ & $101(54.0)$ \\
\hline Rosé (\%) & $7(5.3)$ & $11(5.9)$ \\
\hline All types $(\%)$ & $18(13.6)$ & 25 (13.4) \\
\hline \multicolumn{3}{|c|}{ Number of daily glasses of wine } \\
\hline \multicolumn{3}{|c|}{ Totalt } \\
\hline Mean & 3.9 & 3.5 \\
\hline Median & $4.00(1.25,6.00)$ & $3.0(1.0,6.0)$ \\
\hline \multicolumn{3}{|l|}{ Red $\neq$} \\
\hline Mean & 4.8 & 4.2 \\
\hline Median & $4.0(2.0,6.0)$ & $4.0(2.0,6.0)$ \\
\hline \multicolumn{3}{|l|}{ Whitef } \\
\hline Mean & & \\
\hline Median & $4.5(2.0,8.0)$ & $5.0(2.0,6.5)$ \\
\hline \multicolumn{3}{|l|}{ Roséł } \\
\hline Mean & 7.0 & \\
\hline Median & $6.0(5.0,10.0)$ & $4.0(3.0,9.0)$ \\
\hline \multicolumn{3}{|c|}{ Other alcoholic beverages§ } \\
\hline \multicolumn{3}{|c|}{ Beer } \\
\hline Mean & 4.7 & \\
\hline Median & $0.0(0.0,3.75)$ & $0.0(0.0,3.50)$ \\
\hline \multicolumn{3}{|l|}{ Spirits } \\
\hline Mean & 3.92 & 2.18 \\
\hline Median & $0.0(0.0,2.0)$ & $0.0(0.0,2.0)$ \\
\hline \multicolumn{3}{|c|}{$\begin{array}{l}\text { *Never smokers excluded. Total lifelong tobacco consumption (in thousands of packets). } \\
\text { †All subjects. } \\
\text { tDrinkers only. } \\
\text { \$All subjects. } \\
\text { - Median values (with } 25 \text { th and } 75 \text { th percentiles). } \\
\text { **Defined according to the classification proposed by Ahrens and Merletti }{ }^{15} \text { for those individuals having worked for } \\
\text { more than } 1 \text { year in a risk occupation. }\end{array}$} \\
\hline
\end{tabular}

alcohol consumption of each person. Dietary data for fruit and vegetable intake were also collected using a food frequency questionnaire (FFQ) with a semiquantitative scale with nine categories of consumption (from less than once a month to more than once a day).

\section{Statistical analysis}

Unconditional logistic regression with generalised additive models $(\mathrm{GAM})^{17}$ were used to construct two groups of statistical models: one to assess the effect of consuming each type of wine ("yes/no") and the other to assess the dose-risk relationship for each type. These models were adjusted for sex, age (continuous), occupational exposure to carcinogens (divided into "yes" or "no"), smoking habit, and total alcohol intake. To avoid any possibility of residual confounding resulting from poor control for categorised confounders ${ }^{18}$ or a bad control due to forcing the model to follow a linear relationship (previous studies have shown a saturation relationship among cumulated tobacco and risk of lung cancer ${ }^{19}{ }^{20}$ ), smoking habit was adjusted for the variable "lifelong tobacco consumption" and smoothing splines in GAM with four degrees of freedom. ${ }^{17}{ }^{21}$ Total lifelong tobacco consumption was computed from the following equation: (duration of smoking (in years) $\times$ number of daily cigarettes $\times 365) / 20$.

In the first model the type of wine (classified into "nondrinkers", "white", "red", "rosé", and "all types") was taken as the independent variable. In the second group of models (five models) the independent variables were, respectively, the daily number of glasses of red wine, the daily number of glasses of white wine, the daily number of glasses of rosé, the weekly number of beers, and the weekly number of spirits. Initially, the number of glasses per week was analysed nonparametrically using smoothing splines to assess whether the dose-risk relationship was linear (where the statistical test for non-linearity failed to prove statistically significant). ${ }^{17}$ In those cases where the relationship did prove linear, the variables were included in the model on a straight line parametric basis. To assess the risk of confounding due to smoking or alcohol intake, crude (adjusted only for age and sex) as well as adjusted models were constructed.

\section{RESULTS}

The characteristics of the study subjects are shown in table 1 . The 132 cases with cancer had the following histological types: $55 \%$ epidermoid, $20 \%$ adenocarcinoma, $15 \%$ small cell lung cancer, $9 \%$ large cell lung cancer, and 1\% other. Cases had a higher frequency of having worked in risk occupations and a higher intensity of smoking than the controls. While consumption of spirits was higher in cases than in controls, the consumption of beer was similar in the two groups. It was not possible to analyse the results by sex because the number of women was very low.

Table 2 shows the results by type of wine consumed. Taking non-drinkers as the reference, consumption of red wine was inversely associated with the development of lung cancer which became more pronounced in the multivariate analysis with a final odds ratio (OR) of 0.43 (95\% CI 0.19 to 


\begin{tabular}{|c|c|c|c|c|}
\hline & Cases & Controls & $\begin{array}{l}\text { Crude OR* } \\
(95 \% \mathrm{Cl})\end{array}$ & $\begin{array}{l}\text { Adjusted OR† } \\
(95 \% \mathrm{Cl})\end{array}$ \\
\hline \multicolumn{5}{|l|}{ Type of wine } \\
\hline Non-drinkers & 33 & 41 & 1 & 1 \\
\hline White & 26 & 9 & 3.41 (1.41 to 8.29 ) & $1.47(0.49$ to 4.38$)$ \\
\hline Red & 47 & 101 & $0.55(0.30$ to 1.01$)$ & $0.43(0.19$ to 0.96$)$ \\
\hline Rosé & 7 & 11 & $0.74(0.25$ to 2.16$)$ & 0.35 (0.09 to 1.38 ) \\
\hline All types & 18 & 25 & $0.86(0.39$ to 1.89$)$ & $0.48(0.16$ to 1.40$)$ \\
\hline \multicolumn{5}{|l|}{ Beer } \\
\hline Non-drinkers & 76 & 111 & 1 & 1 \\
\hline Drinkers & 56 & 76 & $1.08(0.67$ to 1.74$)$ & 1.10 (0.59 to 2.08 ) \\
\hline \multicolumn{5}{|l|}{ Spirits } \\
\hline Non-drinkers & 85 & 147 & 1 & 1 \\
\hline Drinkers & 47 & 40 & 2.22 (1.32 to 3.74$)$ & 1.64 (0.79 to 3.40$)$ \\
\hline
\end{tabular}

${ }^{*}$ Adjusted for age and sex.

†Adjusted for age, sex, occupation, smoking habit (total lifelong tobacco consumption in thousands of packets) and total alcohol intake.

0.96). Consumption of white wine, on the other hand, did not show a statistically significant association. Consumption of rosé wine also had a negative association with the development of lung cancer, although there were very few subjects in this category. Consumption of beer appeared to produce no risk for lung cancer. With regard to the consumption of spirits, the crude analysis suggested a positive association with lung cancer which disappeared on adjustment for other confounding variables.

Table 3 shows the results for the amount of white, red, and rosé wine consumed daily. For these purposes, we excluded 43 subjects who reported drinking any type of wine indiscriminately, thereby yielding a total of 276 subjects for inclusion in the final statistical analysis. The non-linearity test showed that dose-risk relationships for consumption of red, white, and rosé wine, beer, and spirits could be assumed to be linear (with p values for linearity of $0.27,0.24,0.17$, 0.65 , and 0.12 , respectively). In terms of the daily number of glasses, white wine appeared to increase the risk (OR 1.20) and the confidence interval did not include 1. Consumption of red wine, on the other hand, was associated with a slight but statistically significant reduction in the development of lung cancer. In the multivariate model neither beer nor spirits had any apparent effect on the development of lung cancer.

When diet was included in the analysis (data not shown), neither fruit nor vegetable intake acted as confounders since the estimated associations hardly changed. We also observed that, when these variables were included in the models (together with tobacco, sex, age, occupation, and total alcohol intake), the confidence intervals became wider.

\section{DISCUSSION}

The results of this study suggest that the potential negative association of wine with the development of lung cancer may depend on the type of wine consumed. There was an

Table 3 Dose-response analysis for alcoholic beverages

\begin{tabular}{lll}
\hline & Crude OR* $(95 \% \mathrm{Cl})$ & Adjusted OR† $(95 \% \mathrm{Cl})$ \\
\hline Red wine $\neq$ & $0.90(0.82$ to 0.99$)$ & $0.87(0.77$ to 0.99$)$ \\
White wine $\neq$ & $1.29(1.12$ to 1.49$)$ & $1.20(1.01$ to 1.42$)$ \\
Rosé $\neq$ & $1.01(0.88$ to 1.16$)$ & $0.97(0.82$ to 1.14$)$ \\
Beer§ & $1.00(0.98$ to 1.02$)$ & $0.99(0.97$ to 1.02$)$ \\
Spirits\$ & $1.04(1.00$ to 1.08$)$ & $1.03(0.97$ to 1.08$)$ \\
\hline
\end{tabular}

*Adjusted for age and sex.

†Adjusted for age, sex, occupation, smoking habit (total lifelong tobacco consumption in thousands of packets), and total alcohol intake. $\ddagger$ By daily number of glasses.

§By weekly unit. indication of an inverse relationship between red wine and lung cancer, with a suggestion of a linear dose-response pattern. On average, the odds ratio per daily glass of red wine consumed was 0.87 (95\% CI 0.77 to 0.99 ).

Earlier studies reporting an inverse association between red wine and lung cancer did not differentiate between the different types of wine consumed. Our study indicates that the results tend to depend, to an important degree, on the particular type of wine drunk, with red wine appearing to offer some protection and white wine having no such effect. However, it should be noted that the number of subjects who drank white wine was far smaller than those who drank red wine. To our knowledge, this is the first epidemiological population based study to have directly studied the effect of the different types of wine on lung cancer, although analyses by wine subtypes were based on a small number of subjects. As with other studies, ${ }^{10}$ there was no clear effect of consumption of spirits or beer on the development of lung cancer.

Not many studies have addressed the effect of alcohol intake on the development of lung cancer, ${ }^{5-13} 22-26$ and even fewer have studied the effect of wine consumption. ${ }^{810-12} 25$ None of the five studies cited draw a direct distinction as to the type of wine consumed (white or red). The study by Prescott $e t \mathrm{al}^{8}$ undertaken in Denmark indicated that $75 \%$ of Danish wine drinkers favoured red wine and reported an effect of 0.78 (95\% CI 0.63 to 0.97 ) and 0.44 (95\% CI 0.22 to $0.86)$ for the second and third categories of consumption, respectively. These results are very similar to those observed by us. Other studies, despite not indicating the type of wine consumed, also report a negative association with lung cancer. ${ }^{10}{ }^{11}$ Some studies have reported, somewhat inconsistently, a certain risk for consumption of red wine. Indeed, De Stefani et $a l^{12}$ observed a risk of 1.5 (95\% CI 0.9 to 3.3) for wine intake, while noting that most of the wine consumed in Uruguay was red. The controls used in this study were cancer patients, albeit with neoplasias that were non-alcohol and non-tobacco related. Another study conducted on Polish women $^{25}$ found a risk of 2.60 (95\% CI 1.55 to 4.38) for those drinking $\geqslant 70 \mathrm{~g}$ alcohol in the form of wine. It should be stressed that these results were not adjusted for tobacco consumption and no differentiation was made for the type of wine. Wine consumption has also been reported to have a negative association with other cancers of the upper digestive tract, although again no differentiation was made for the specific type of wine consumed. ${ }^{27}$ The authors of these studies $^{81127}$ attribute the potential protective effect (considered overall) to the effect of red wine. Nevertheless, failure to differentiate for type of wine means that the observed effect 
could be due to the potential effect of substances common to both red and white wine. However, our study seems to indicate that the inverse association is due to substances specifically contained in red wine.

The effect of red wine on lung cancer might be attributable to the fact that it contains a higher proportion of tannins (which have antioxidant properties) and resveratrol, a substance that has been experimentally shown to inhibit tumour initiation, promotion, and progress. ${ }^{28}$ This anticarcinogenic property was first described in 1997 in rodents and has subsequently been confirmed by research on human models. ${ }^{29}$ Accordingly, it has been proposed that resveratrol might exert its preventive activity by a dose-dependent reduction in benzopyrenediolepoxide derivative formation and inhibiting phase I CYPIAl and CYPIBl gene expression in bronchial epithelial cells. ${ }^{29}$ These factors would explain the decreased risk of lung cancer in smokers consuming red wine (data not shown). Furthermore, Ahrendt et a ${ }^{24}$ indicated that ethanol might also produce mutations in the p53 gene, although they failed to analyse consumption of wine which contains lower quantities of ethanol than spirits. In view of our results, it seems that the anticarcinogenic properties of red wine amply outweigh the damaging effect of alcohol on this gene, although there might be an antagonistic effect between alcohol intake and consumption of red wine at high doses.

With respect to white wine, we not only showed consumption to be less frequent than that of red but also found a differential effect between the two. In the doseresponse analysis there was a significant positive association with white wine (OR per glass 1.20). However, it should be noted that the number of subjects consuming white wine was low. Consumption of rosé, whose composition is midway between red and white, did not appear to have any effect in the dose-response model. There was a suggestion of an inverse relationship but the confidence interval included zero.

Wine is considered to be the least of all the alcoholic beverages to be associated with smoking; ${ }^{56}$ this was confirmed in our study and serves to reduce the possibility of a distortion of the effect caused by residual confounding. Any exposure possibly associated with tobacco use (such as consumption of alcohol) may have an association with lung cancer due to a potential confounding effect that has not been properly controlled for. In the case of smoking and lung cancer, the association is so strong that, even where tobacco use is controlled for, the variable of the adjustment used (number of cigarettes/day, lifelong consumption, or duration of habit) may nevertheless influence the result of the analysis. In our case, adjustment was made for lifelong tobacco consumption because it includes the daily number of cigarettes smoked and the duration of the habit, and is therefore the variable which best reflects tobacco use. It was included non-parametrically as a continuous variable, thereby reducing the possibility of residual confounding still further..$^{30}$ The same was done for total alcohol intake. The confounding effect of tobacco can be observed by comparing the crude and adjusted results: initially, consumption of spirits appeared to be an important risk factor (with a statistically significant doubling in the risk) but this disappeared on adjustment for tobacco. A further advantage of the study is that wine consumption is much higher in Spain-and especially in the study area-than in other populations, so its effect can be more easily observed at high doses. In other countries the study of the effect of wine intake is hindered by very low consumption. ${ }^{26}$

Diet has been shown to affect the development of lung cancer. ${ }^{31-34}$ In this study neither fruit nor vegetable intake modified the effect of each type of wine. This may be because the protective effect observed for fruit and vegetable intake is of a low magnitude in most studies, so studies with a larger sample size are needed to observe a protective effect. This was not the case in the present study.

This study has a number of limitations, some of which are inherent to case-control studies. The main limitation is that exposure is measured retrospectively so the possibility of a recall bias cannot be excluded. We tried to conduct the interview similarly in both cases and controls to overcome this bias. A further limitation is that subjects were not asked about the number of years during which they had consumed wine or other alcoholic beverages. We nevertheless feel that this habit is one that is maintained over time. A recent study by Freudenheim et $a l^{35}$ did not find an association between lifetime alcohol intake and the risk of lung cancer, although there was some suggestion of an increased risk with recent intake. One problem of all case-control studies is the possibility of differences in the quality of the information given between cases and controls, as cases can overestimate or underestimate their past exposures. We tried to avoid this bias by interviewing cases within 15 days of diagnosis and asking them about their consumption of alcoholic beverages before the date of onset of disease symptoms. It might also be thought that the selection of hospital controls could alter the results, but none of the surgical interventions for which controls were selected (cataracts, inguinal hernias, and orthopaedic surgery) has been associated with higher alcohol consumption. Although the results obtained indicate that the effect of wine consumption is linear, the size of the study sample is insufficient to determine whether or not the effect would continue to be linear in studies with a larger sample. The linearity test has also little statistical capacity to detect non-linearity for values based on a few subjects (as is the case for high intake of wine). Further research is therefore needed to examine the effect of wine at high doses.

We conclude that the consumption of red wine might have an inverse association with the development of lung cancer. This effect appears to follow a dose-response gradient and is robust, remaining in evidence when adjustment is made for tobacco consumption, occupation, and total alcohol consumption. From a public health standpoint, however, we feel that these results should be approached with caution as it would be extremely risky - and even dangerous-for recommendations to be drawn up endorsing a high consumption of red wine for the prevention of lung cancer in the light of the well known association between alcohol consumption and increased mortality. However, our results could be used to identify the components of red wine associated with this possible protective effect and to recommend the consumption of these to smokers.

\section{ACKNOWLEDGEMENTS}

The authors are grateful to Michael Benedict and Dr Carlos Fernandez Gonzalez for their comments on the manuscript.

\section{Authors' affiliations}

A Ruano-Ravina, A Figueiras, J M Barros-Dios, Department of Preventive Medicine and Public Health, University of Santiago de Compostela, Spain

A Ruano-Ravina, Galician Agency for Health Technology Assessment, Galician Health Service, Spain

J M Barros-Dios, Preventive Medicine Unit, Santiago de Compostela University Teaching Hospital, Spain

This work was supported by a University Lecturer Training Grant from the Spanish Ministry of Education and Culture (AP98-32819076). The grant was obtained by A Ruano-Ravina and was used for doing his doctoral thesis.

Conflict of interest: none 


\section{REFERENCES}

1 Ferlay J, Bray F, Pisani P, et al. GLOBOCAN 2000: cancer incidence, mortality and prevalence worldwide, Version 1.0.IARC CancerBase No.5. Lyon, IARC Press, 2001 (limited version available from http://wwwdep.iarc.fr/globocan/globocan.html).

2 Parkin DM, Pisani $P$, López $A D$, et al. At least one in seven cases of cancer is caused by smoking. Global estimates for 1985. Int J Cancer 1994; 59:494-504.

3 Hecht SS. Tobacco smoke carcinogens and lung cancer. J Natl Cancer Inst 1999;91:1194-210.

4 World Cancer Research Fund \& American Institute for Cancer Research. Food, nutrition and the prevention of cancer: a global perspective. Washington DC: American Institute for Cancer Research, 1997.

5 Bandera EV, Freudenheim JL, Vena JE. Alcohol consumption and lung cancer: a review of the epidemiologic evidence. Cancer Epidemiol Biomarkers Prevention $2001 ; 10: 813-21$

6 Korte JE, Brennan P, Henley SJ, et al. Dose-specific meta-analysis and sensitivity analysis of the relation between alcohol consumption and lung cancer risk. Am J Epidemiol 2002;155:496-506.

7 Bandera EV, Freudenheim JL, Graham S, et al. Alcohol consumption and lung cancer in white males. Cancer Causes Control 1992;3:361-9.

8 Prescott E, Groenbaek M, Becker U, et al. Alcohol intake and the risk of lung cancer: influence of type of alcoholic beverage. Am J Epidemiol 1999; 149:463-70.

9 Bandera EV, Freudenheim JL, Marshall JR, et al. Diet and alcohol consumption and lung cancer risk in the New York State cohort (United States). Cancer Causes Control 1997;8:828-40.

10 Woodson K, Albanes D, Tangrea JA, et al. Association between alcohol and lung cancer in the alpha-tocopherol, beta-carotene cancer prevention study in Finland. Cancer Causes Control 1999;10:219-26.

11 Carpenter CL, Morgenstern H, London SJ. Alcoholic beverage consumption and lung cancer risk among residents of Los Angeles county. J Nutr 1998; 128:694-700.

12 De Stefani E, Correa P, Fierro L, et al. The effect of alcohol on the risk of lung cancer in Uruguay. Cancer Epidemiol Biomarkers Prevention 1993;2:21-6.

13 Dioussé L, Dorgan JF, Zhang Y, et al. Alcohol consumption and risk of lung cancer: the Framingham study. J Natl Cancer Inst 2002;94:1877-82.

14 Ruano-Ravina A. Estudio de casos y controles sobre factores de riesgo y susceptibilidad genética en el cáncer de pulmón, Doctoral thesis.Department of Preventive Medicine and Public Health, University of Santiago de Compostela, 2001.

15 Ahrens W, Merletti F. A Standard tool for the analysis of occupational lung cancer in epidemiologic studies. Int J Occup Environ Health 1998;4:236-40.

16 Ruano-Ravina A, Figueiras A, Barros-Dios JM. Occupation and smoking as risk factors for lung cancer: a population-based case-control study. Am J Ind Med 2003;43:149-55.

17 Hastie TJ, Tibshirani RJ. Generalized additive models. London: Chapman and Hall, 1990.
18 Brenner $\mathrm{H}$, Blettner M. Controlling for continuous confounders in epidemiologic research. Epidemiology 1997;8:429-34.

19 Leffondre K, Abrahamowicz M, Siemiatycki J, et al. Modeling smoking history: a comparison of different approaches. Am J Epidemiol 2002;156:813-23.

20 Ruano-Ravina A, Figueiras A, Montes-Martinez A, et al. Dose-response relationship between tobacco and lung cancer: new findings. Eur $J$ Cancer Prev 2003; 12:257-63.

21 Figueiras A, Cadarso-Suarez C. Application of nonparametric models for calculating odds ratios and their confidence intervals for continuous exposures. Am J Epidemiol 2001;154:264-75.

22 Boffetta P, Ye W, Adami HO, et al. Risk of cancers of the lung, head and neck in patients hospitalized for alcoholism in Sweden. Br J Cancer 2001:85:678-82.

23 Zang EA, Wynder EL. Re-evaluation of the confounding effect of cigarette smoking on the relationship between alcohol use and lung cancer risk, with larynx cancer used as a positive control. Prev Med 2001;32:359-70.

24 Ahrendt SA, Chow JT, Yang SC, et al. Alcohol consumption and cigarette smoking increase the frequency of p53 mutations in non-small cell lung cancer. Cancer Res 2000:60:3155-9.

25 Rachtan J. Alcoholic beverages consumption and lung cancer cell types among women in Poland. Lung Cancer 2002;35:119-27.

26 Potter JD, Sellers TA, Folsom AR, et al. Alcohol, beer, and lung cancer in premenopausal women. The lowa Women's Health Study. Ann Epidemiol 1992;2:587-95.

27 Groenbaek M, Becker U, Johansen D, et al. Population based cohort study of the association between alcohol intake and cancer of the upper aerodigestive tract. BMJ 1998;317:844-8.

28 Jang M, Cai L, Udeani GO, et al. Cancer chemoprevention activity of resveratrol, a natural product derived from grapes. Science 1997;275:218-20.

29 Mollerup S, Ovrebo S, Haugen A. Lung carcinogenesis: resveratrol modulates the expression of genes involved in the metabolism of PAH in human bronchial epithelial cells. Int J Cancer 2001;92:18-25.

30 Brenner $\mathrm{H}$, Blettner $\mathrm{M}$. Controlling for continuous confounders in epidemiologic research. Epidemiology 1997;8:429-34.

31 Knekt $P$, Järvinen $R$, Seppänen $R$, et al. Dietary flavonoids and the risk of lung cancer and other malignant neoplasms. Am J Epidemiol 1997;146:223-30.

32 Ziegler RG, Taylor Mayne S, Swanson CA. Nutrition and lung cancer. Cancer Causes Control 1996;7:157-77.

33 Männistö S, Smith-Warner SA, Spiegelman D, et al. Dietary carotenoids and risk of lung cancer in a pooled analysis of seven cohort studies. Cancer Epidemiol Biomarkers Prevention 2004:13:40-8.

34 Ruano-Ravina A, Figueiras A, Dosil-Diaz O, et al. A population-based casecontrol study on fruit and vegetable intake and lung cancer: a paradox effect? Nutr Cancer 2002;43:47-51.

35 Freudenheim JL, Ram M, Nie J, et al. Lung cancer in humans is not associated with lifetime total alcohol consumption or with genetic variation in alcohol dehydrogenase 3 (ADH3). J Nutr 2003;133:3619-24. 